\title{
The Relationship Between Spiritual Intelligence and Psychological Well-Being in Women with Breast Cancer
}

\author{
Khadijeh Ahoei, ${ }^{1}$ Mahbobeh Faramarzi, ${ }^{2,}$ and Ramezan Hassanzadeh ${ }^{3}$ \\ ${ }^{1}$ Islamic Azad Univercity, Sari Branch, Sari, Iran \\ ${ }^{2}$ Social Determinants of Health Research Center, Babol University of Medical Sciences, Babol, Iran \\ ${ }^{3}$ Department of Psycology, Islamic Azad University, Sari Branch, Sari, Iran \\ "Corresponding author: Mahbobeh Faramarzi, PhD of Psychology, Associate Professor, Social Determinants of Health Research Center, Babol University of Medical Sciences, \\ Babol, Iran. E-mail: mahbob330@yahoo.com
}

Received 2017 May 02; Revised 2017 June 12; Accepted 2017 August 19.

\begin{abstract}
Background: As crisis caused by cancer results in imbalances and inconsistencies in body and mind as well as many psychological problems in patient's life, spiritual intelligence is a critical source to increase resistance to the disease. This study aimed to investigate the relationship between spiritual intelligence and psychological well-being in women with breast cancer in Babol.

Methods: This descriptive-correlational study was conducted in the spring 2016 on 90 women with breast cancer referring for treatment to Shahid Rajaei hospital of Babolsar, and Ayatollah Rouhani and the counseling center for cancer registry of Babol. Demographic characteristics of patients such as age, marital status, education, occupation, place of residence (urban or rural), and duration of illness were recoded. In addition, two questionnaires of spiritual intelligence self-report inventory (SISRI-24) and Brief Reef Well-Being (18 questions) were used.

Results: The results showed that the mean score of spiritual intelligence was $69.90 \pm 14.13$ (range of 0 - 98 ) and the mean score of psychological well-being was $75.01 \pm 12.10$ (range of 1 - 108). There was a significant relationship between spiritual intelligence and psychological well-being $(r=0.47)$. The results of multiple regression analysis showed that spiritual intelligence predicted $22 \%$ of variance of psychological well-being. Among the demographic characteristics, only the relationship between education and psychological well-being was significant $(r=0.2)$. Based on the results of backward regression analysis, demographic variables were excluded from the model due to the lack of statistically significant relationship with psychological well-being, and only spiritual intelligence variable $(B=0.41)$ was identified as the strong independent predictor of psychological well-being of cancer patients in the final model.

Conclusions: It is recommended for cancer treatment and cancer support centers to improve the skills of spiritual intelligence in women with breast cancer, especially in terms of personal meaning production, to promote psychological well-being.
\end{abstract}

Keywords: Psychological Well-Being, Breast Cancer, Spiritual Intelligence

\section{Background}

Breast cancer is the most common and most troubling health problem in the world (1). It is estimated that breast cancer accounts for about 30\% of women's cancer (2). More than 1.1 million women worldwide are diagnosed with breast cancer annually and more than 410 thousand of them die of the disease (3). The risk of breast cancer in Iranian women is 27.5 in one hundred thousand (4).

Getting informed about having cancer is a surprising (5) and disturbing experience for everyone (6). Various studies have shown that there is a close connection between cancer and psychological status (7). The crisis caused by cancer will result in imbalances and inconsistencies in body and mind and it encounters patient's life with many psychological problems.

Psychological well-being refers to the quality of experienced life and reflects the desirable functional and psy- chological experience (8). Reef has identified six factors as psychological well-being criteria: self-acceptance (the ability to see and accept your strengths and weaknesses), having purpose in life (having meaning in life), personal growth (growing one's potentials to reality), having positive relationships with others (close and valuable ties with others), environmental mastery (the ability to set and manage daily issues of life) and finally, independence (the ability to follow the personal principles even if they disagree with social demands and traditions) (9).

Based on research, cancer can affect person's psychological well-being. Cancer experience may be accompanied by growth, change, discomfort, and challenges such as distress for diagnosis and treatment, death, shock, anxiety and depression, guilt and blame, feeling of isolation, and negative body image (10). Ferrell et al. in their study stated that there are significant stressors at all stages of diagnosis, treatment, recovery, and recurrence (11). The re- 
sults of Zamani et al. study showed that cancer patients had a lower quality of life and psychological well-being than diabetics and patients with multiple sclerosis (12).

One of the factors affecting psychological well-being is spirituality. In the heart and mind of all individuals, spirituality can be observed in religious habits and behaviors everywhere and it has a significant positive impact on their lives. Having meaning and purpose in life, enjoying social and spiritual support, sense of belonging to a top source, having a good spiritual life, etc. are the ways through which people can reduce the damage of stressful events in life (13). Soleimani et al. (14) concluded that religious orientation especially intrinsic one can be a strong predictor of psychological well-being. Besides, different studies have mentioned the relationship of religious beliefs (15) and spirituality (16) with psychological well-being.

King believes that spiritual intelligence creates a unique capacity and capability to understand the meaning of life and to reach a higher spiritual status. His four-factor model of spiritual intelligence includes critical thinking about reality of being, creating personal meaning (the ability to use physical and psychological experiences to create personal meaning and goals), transcendental consciousness (the ability to identify transcendental self-aspects, others, and the world using consciousness), and providing alertness opportunities (to enter the higher spiritual positions, including deep thought, prayer, and meditation). Spiritual intelligence represents a set of abilities and capacities of spiritual resources to be applied in daily life to enhance the adaptability of individuals (17).

Due to the increasing number of patients with breast cancer and the importance of mental problems because of their impact on all aspects of life of patients, especially women, and the lack of a published report on the situation of psychological well-being among breast cancer patients in Iran, this study aimed to not only describe the components of psychological well-being of patients such as self-acceptance, positive relations with others, autonomy, environmental mastery, purposeful life and personal growth, but also examine their relationship with the dimensions of spiritual intelligence (critical thinking, creating personal meaning, transcendental consciousness, and expanded state of consciousness) and answer this important question: how much is the predictive power of spiritual intelligence regarding psychological well-being of women with breast cancer?

\section{Methods}

This descriptive study was conducted in the spring 2016 on 90 women with breast cancer referring for treatment or advice to Shahid Rajaei hospital of Babolsar, Aya- tollah Rouhani and the counseling center for cancer registry of Babol. The sample size was determined by convenience sampling method using a software for calculating the sample size for correlational studies. To calculate the sample size, the questionnaires were first completed by 30 cases of target population based on study protocol. Then, the data were entered into SPSS software. The preliminary results showed 0.366 correlation between the variables. According to the degree of correlation and considering 5\% Type I and type II errors (alpha and beta), the data were entered into Gpower 3 software for sample size calculation.

After getting permission from Babol University of Medical Sciences, a researcher referred to the hospitals and centers to collect data. Eligible patients with more than 5 years of education were invited to enter the study. The researcher conducted an interview with the patients. She gave brief explanations regarding the purpose of the study. The subjects were also assured their response would be treated with utmost confidentiality. The researcher collected demographic data. Then, she asked the patients to complete two questionnaires including spiritual intelligence self-report inventory (SISRI-24) and Brief Reef WellBeing (18 questions). All patients gave their informed consent. This study was approved by the Ethics Committee of Islamic Azad University of Sari under 24-1394 Code.

Demographic questionnaire: It included age, marital status, education, occupation, place of residence (urban or rural), and duration of illness.

Spiritual Intelligence Self-report Inventory (SISRI-24): It was developed by King (2008).

This scale consists of 24 questions with a scoring system based on a five-point Likert scale (strongly agree $=4$, agree $=3$, no idea $=2$, disagree $=1$, strongly disagree $=$ $0)$. The total score ranges from 0 to 96 (17). It is composed of four subscales including critical existential thinking, personal meaning production, consciousness, and expanded state of consciousness (18). The Persian version of the questionnaire was validated by Abdollah Zadeh in 1999. The validity of the scale was confirmed with Cronbach's alpha of 0.85 (19). Total and subscales reliability were reported based on Cronbach's alpha as coefficients of 0.95 , $0.87,0.89$, and 0.94 , respectively (20).

Brief Reef Well-Being (18 questions): This questionnaire evaluates 6 main components of psychological well-being: self-acceptance (positive attitude towards self and acceptance of different aspects), positive relations with others (sense of satisfaction and intimacy with people), autonomy (sense of independence and having ability to affect life events), environmental mastery (sense of controlling outdoor activities), purposeful life (having a purpose in life), and personal growth (sense of steady growth and hav- 
ing access to new experience). The scoring system is based on the whole 6-point Likert scale ( $1=$ strongly disagree to 6 = strongly agree). The total score ranges from 1 to 108 (21). The reliability of the test was determined by its correlation with Bradburn's emotional balance scale, Neugarten life satisfaction, and Rosenberg self-esteem; the correlation results of Reef test with any of the above measures were acceptable (20).

The data were analyzed using statistical software SPSS version 22. The descriptive statistics (frequency, mean, and standard deviation) and inferential statistics (Pearson correlation coefficient, independent t test, and linear regression) were used for detailed description of the study population. P values less than 0.05 were considered significant.

\section{Results}

The mean age of the patients was $45.98 \pm 9.74$ the age range was 24 - 70 years. Table 1 represents demographic characteristics of the subjects.

Table 1. Descriptive Statistics of Demographic Data of Patients

\begin{tabular}{l|c|c|c}
\hline \multirow{4}{*}{ Variables } & Groups & Frequency & Percentage \\
\hline \multirow{4}{*}{ Education } & $50<$ & 57 & 63.3 \\
\cline { 2 - 4 } & $50 \geq$ & 33 & 36.7 \\
\cline { 2 - 4 } & Secondary school & 30 & 44.5 \\
\cline { 2 - 4 } & High school & 36 & 40.0 \\
\hline \multirow{4}{*}{ Residence } & University & 14 & 15.5 \\
\hline \multirow{3}{*}{ Marital status } & City & 56 & 62.2 \\
\cline { 2 - 4 } & Village & 34 & 37.8 \\
\hline \multirow{2}{*}{ Occupation } & Married & 75 & 83.3 \\
\cline { 2 - 4 } & Single & 15 & 16.7 \\
\hline \multirow{4}{*}{ Duration of illness, $\mathbf{y}$} & Employed & 12 & 13.3 \\
\cline { 2 - 4 } & Housewife & 78 & 86.7 \\
\cline { 2 - 4 } & $\mathbf{2}$ & 55 & 61.1 \\
\hline
\end{tabular}

${ }^{\mathrm{a}}$ Single, divorced or widow.

Among the aspects of spiritual intelligence, critical thinking had the highest and expanded state of consciousness had the lowest share in spiritual intelligence score. Among the components of psychological well-being, environmental mastery had the highest and purposeful life had the lowest effect (Table 2).

Table 3 shows the correlation of components of spiritual intelligence with the components of psychological well-being. The results of Pearson correlation coefficient test indicated a positive significant relationship between spiritual intelligence and psychological well-being. Psychological well-being was highly correlated with personal meaning production while the lowest correlation was with expanded state of consciousness. Although different aspects of psychological well-being were significantly associated with spiritual intelligence, purposeful life had no significant relationship with spiritual intelligence.

Table 4 shows the results of linear regression test in a separate univariate examination between psychological well-being or spiritual intelligence and demographic variables. The findings suggested that spiritual intelligence could predict $22 \%$ of variance of psychological well-being. To show the results of multivariate analysis (adjusted effects), backward modeling was used in linear regression at the same time to examine psychological well-being and spiritual intelligence in the presence of all the variables in the model, due to the insignificance of many variables. All demographic variables were excluded because of the lack of a statistically significant relationship with psychological well-being, and the only variable remaining in the final model was spiritual intelligence. This variable was identified as an independent and strong predictor, so that for every one-unit increase in spiritual intelligence, 0.41 unit was added to the psychological well-being score (Table 5).

\section{Discussion}

The aim of this study was to investigate the relationship between psychological well-being and spiritual intelligence. The results showed a significant relationship between spiritual intelligence and psychological well-being and its different dimensions among women with breast cancer. In other words, patients with higher spiritual intelligence had also higher psychological well-being. These results are in line with the study findings of Sahebalzamani et al. (22) on nurses indicating that spiritual intelligence can integrate inner life and outside life. Hence, it was mentioned as an individual's ability to adapt to environment. In this sense, spiritual intelligence represents a set of abilities, capacities, and intellectual resources, which can increase a person's adaptability and psychological well-being.

Since there was no study conducted to examine the relationship between spiritual intelligence and psychological well-being in cancer, similar studies were used to make comparisons. Numerous studies have reported a significant inverse correlation between Spiritual Intelligence and depression or other mental health problems among patients with cancer (23). Sim and Loh believed that spiritual 
Table 2. The Mean and Standard Deviation of Variables

\begin{tabular}{|c|c|c|c|c|c|}
\hline Scale & Scores Range & Mean & SD & Min & Max \\
\hline Spiritual intelligence & $0-96$ & 69.90 & 14.13 & 13 & 96 \\
\hline Psychological well-being & $1-108$ & 75.01 & 12.10 & 30 & 100 \\
\hline
\end{tabular}

Table 3. Pearson Correlation Coefficients of Spiritual Intelligence Components and Different Aspects of Psychological Well-Being

\begin{tabular}{|c|c|c|c|c|c|c|c|}
\hline Components & Self-Acceptance & $\begin{array}{c}\text { Positive } \\
\text { Relationship } \\
\text { with Others }\end{array}$ & Autonomy & $\begin{array}{c}\text { Environmental } \\
\text { Mastery }\end{array}$ & Purposeful Life & Personal Growth & $\begin{array}{l}\text { Psychological } \\
\text { Well-Being }\end{array}$ \\
\hline $\begin{array}{l}\text { Critical } \\
\text { existential } \\
\text { thinking }\end{array}$ & $0.29^{\mathrm{a}}$ & $0.27^{\mathrm{a}}$ & $0.30^{\mathrm{a}}$ & $0.30^{\mathrm{a}}$ & 0.13 & $0.41^{\mathrm{a}}$ & $0.43^{\mathrm{a}}$ \\
\hline $\begin{array}{l}\text { Personal } \\
\text { meaning } \\
\text { production }\end{array}$ & $0.34^{\mathrm{a}}$ & $0.36^{\mathrm{a}}$ & $0.32^{\mathrm{a}}$ & $0.33^{\mathrm{a}}$ & 0.19 & $0.48^{\mathrm{a}}$ & $0.51^{\mathrm{a}}$ \\
\hline Consciousness & $0.38^{\mathrm{a}}$ & $0.37^{\mathrm{a}}$ & $0.32^{\mathrm{a}}$ & $0.32^{\mathrm{a}}$ & 0.08 & $0.45^{\mathrm{a}}$ & $0.48^{\mathrm{a}}$ \\
\hline $\begin{array}{l}\text { expanded state } \\
\text { of consciousness }\end{array}$ & $0.25^{\mathrm{b}}$ & $0.24^{\mathrm{b}}$ & 0.14 & $0.22^{\mathrm{b}}$ & 0.01 & $0.29^{\mathrm{a}}$ & $0.30^{\mathrm{a}}$ \\
\hline $\begin{array}{l}\text { Spiritual } \\
\text { intelligence }\end{array}$ & $0.35^{\mathrm{a}}$ & $0.34^{\mathrm{a}}$ & $0.30^{\mathrm{a}}$ & $0.32^{\mathrm{a}}$ & 0.11 & $0.45^{\mathrm{a}}$ & $0.47^{\mathrm{a}}$ \\
\hline $\begin{array}{l}{ }^{\mathrm{a}} \mathrm{P}<0.001 \\
{ }^{\mathrm{b}} \mathrm{P}<0.05\end{array}$ & & & & & & & \\
\hline
\end{tabular}

Table 4. The Relationship Between Psychological Well-Being and Variables of the Study by Univariate Analysis

\begin{tabular}{|c|c|c|c|c|c|}
\hline Variables & B (SE) & Beta & P Value & $\% 95 \mathrm{CI}$ & R Square \\
\hline Spiritual intelligence & $0.41(0.08)$ & 0.47 & 0.000 & $0.25-0.56$ & 0.22 \\
\hline Age, $y$ & $-0.09(0.13)$ & -0.07 & 0.483 & $-0.35-0.16$ & 0.006 \\
\hline Education, $y$ & $0.57(0.31)$ & 0.18 & 0.075 & $-0.06-1.20$ & 0.03 \\
\hline Residence (city or village) & $0.97(2.64)$ & 0.04 & 0.713 & $-4.28-6.23$ & 0.002 \\
\hline Occupation (employed/housewife) & $-1.33(3.64)$ & -0.04 & 0.715 & $-8.58-5.91$ & 0.002 \\
\hline Marital status (married/ single/ etc.) & $-2.33(3.43)$ & -0.07 & 0.499 & $-9.15-4.49$ & 0.005 \\
\hline Duration of illness $(\geq 3 /<3)$ & $1.05(2.63)$ & 0.04 & 0.689 & $-4.17-6.28$ & 0.002 \\
\hline
\end{tabular}

Table 5. The Relationship Between Psychological Well-Being and Variables Of the Study (Multivariate Analysis) ${ }^{\mathrm{a}}$

\begin{tabular}{lcccc}
\hline Variable & B (SE) & Beta $^{\mathbf{b}}$ & P Value $^{\mathbf{c}}$ & \%95 CI $^{\mathbf{c}}$ \\
\hline Spiritual intelligence & $0.41(0.08)$ & 0.47 & 0.000 \\
\hline
\end{tabular}

Abbreviation: CI, Confidence Interval.

${ }^{\mathrm{a}}$ The regression linear test was used - Backward model

${ }_{\mathrm{b}}^{\mathrm{b}} \mathrm{B}$; slope of regression. Beta; correlation.

${ }^{\mathrm{c}}$ Significance level of $\mathrm{P}<0.05$.

intelligence could create meaning and purpose in life; people with this characteristic can better cope with conditions in times of crisis, because they have hope in God and therefore, they experience less psychological distress (24). Studies have shown that spiritual intelligence has a significant impact on the perception of pain in patients with cancer (25). The results of Charkhabi et al. suggested that training spiritual intelligence as a new psychological and religious structure can reduce mental disaster and improve mental health (26). 
Another result of the study was that spiritual intelligence had the most relevant relationship with personal growth (a component of psychological well-being) and had no meaningful relationship with purposeful life. Among the dimensions of spiritual intelligence, personal meaning production was highly associated with psychological well-being; these results are consistent with the findings of similar studies $(27,28)$. McSherry et al. emphasized that spiritual intelligence is the foundation of personal beliefs and can affect performance, so that it can format the real-life. Spiritual intelligence can increase the flexibility and consciousness, so that the individual can be more patient when facing problems and difficulties of life (29). In their study, Amirian et al. concluded that spiritual intelligence has a positive correlation with public health, and among the components of spiritual intelligence, critical thinking has an inverse significant relationship with general health (30).

Another aspect of psychological well-being defined by Reef was having purpose in life; spiritual intelligence is defined as human ability to ask ultimate questions about the meaning of life and about our experience in the real world as well as human ability to apply, reveal, and include the spiritual resources, values, and quality in order to increase daily performance and psychological well-being; thus, it is expected to exist a relationship between these two variables (31).

There are some limitations for the study. They include rely on self-report outcomes that could distort reality provided by patients, the limitations in secluding patients, the shortage of the history of similar research inside and outside the country, low sample size, and lack of betweengroup comparisons.

\subsection{Conclusion}

According to the results of this study, there is a positive correlation between spiritual intelligence and psychological well-being. Since other studies have reported similar results about the effect of education on spiritual intelligence, it is recommended to design systemic programs to teach women with breast cancer about skills of spiritual intelligence and psychological well-being in workshops. Given the high prevalence of psychological disorders in patients with chronic diseases, especially cancer, it is important to consider psychological well-being factors such as family and community support in treating patients with cancer. In addition, according to these findings, it is suggested for cancer treatment and cancer support centers to promote the spiritual intelligence skills of women with breast cancer, especially in the field of personal meaning, to improve psychological well-being of these patients, particularly their personal growth.
To our knowledge, this is the first study published in the country to evaluate the status of psychological wellbeing and spiritual intelligence in breast cancer patients, which emphasizes the need for providing psychological support to these patients.

\section{Acknowledgments}

Hereby, the kind cooperation of health department officials of Ayatollah Rouhani hospital of Babol, Shahid Rajaei hospital of Babolsar and Babol University of Medical Sciences is highly appreciated.

\section{Footnotes}

Authors' Contribution: The study concept and design, drafting of the manuscript, and revision of the manuscript were conducted by Mahbobeh Faramarzi, Ramezan Hassanzadeh and Khadijeh Ahoei. The data were collected by Khadijeh Ahoei and Mahbobeh Faramarzi, Ramezan Hassanzadeh and Khadijeh Ahoei participated in technical and material support.

Financial Disclosure: The research deputy of Islamic Azad University, Sari Branch.

Conflict of Interests: The authors declare no conflict of interest.

Funding/Support: This paper is derived from a Master's thesis in psychology.

\section{References}

1. WHO . Screening for Breast Cancer 2016. Available from: http://www. who.int/cancer/detection/breastcancer/en/.

2. Harris JR, Lippman ME, Morrow M, Osborne CK. Diseases of the Breast: Wolters Kluwer. 5th ed. United States: Health; 2014.

3. American Cancre Society . Breast cancer facts \& figures Atlanta 2013. Available from: http://www.cancer.org/acs/groups/content/ @ research/documents/document/acspc-042725.pdf.

4. Motevalizadeh Ardakani A, Boroumand M. Cancer and prevention. tehran: Press battlefield of art and ideas; 2014.

5. Akyüz A, Güvenç G, Üstünsöz A, Kaya T. Living with gynecologic cancer: Experience of women and their partners. J Nurs Sch. 2008;40(3):241-7. doi: 10.1111/j.1547-5069.2008.00232.x.

6. Hounsgaard L, Petersen LK, Pedersen BD. Facing possible illness detected through screening-experiences of healthy women with pathological cervical smears. Eur J Oncol Nurs. 2007;11(5):417-23. doi: 10.1016/j.ejon.2007.04.005. [PubMed: 17604694].

7. Pedram Razi S, Haghighat S, Jarban M, Parsa Yekta Z, Agha Hosseini F. The effect of Reflexology on Quality of Life of breast cancer patients during chemotherapy. Iran Q J Breast Dis. 2013;6(1):23-34.

8. Deci EL, Ryan RM. Hedonia, eudaimonia, and well-being: an introduction.J Happiness Stud. 2006;9(1):1-11. doi:10.1007/s10902-006-9018-1.

9. Diener E, Lucas R, Oishi S. In: The handbook of positive psychology. Snyder CR, Lopez SJ, editors. New York: Oxford University Press; 2002. Subjective well-being: The science of happiness and life satisfaction. 
10. Nathan L. Psychological and spiritual well- being of women with breast cancer participating in the art of living program. Nova Science publishers; 2012.

11. Ferrell B, Smith SL, Cullinane CA, Melancon C. Psychological well being and quality of life in ovarian cancer survivors. Cancer. 2003;98(5):1061-71. doi: 10.1002/cncr.11291. [PubMed: 12942576].

12. Zamani S, Ashrafi S, Hajializadeh K, editors. Compare psychological well-being and quality of life in patients with chronic. International Conference on Research in Social and Behavioral Sciences. 2015; Turkey, Istanbul. Institute of Directors thinker capital Eiliya.

13. Wong CS, Law KS. The effects of leader and follower emotional intelligence on performance and attitude. Leadership Q. 2002;13(3):243-74. doi:10.1016/s1048-9843(02)00099-1.

14. Soleimani Khashab A, Mansouri Khashab A, Mohammadi MR, Zarabipour H, Malekpour V. Predicting dimensions of psychological well being based on religious orientations and spirituality: an investigation into a causal model. Iran J Psychiatry. 2015;10(1):50-5. [PubMed: 26005481].

15. Kaliampos A, Roussi P. Religious beliefs, coping, and psychological well-being among Greek cancer patients. J Health Psychol. 2017;22(6):754-64. doi: 10.1177/1359105315614995. [PubMed: 26613708].

16. Visser A, Garssen B, Vingerhoets A. Spirituality and well-being in cancer patients: a review. Psychooncology. 2010;19(6):565-72. doi: 10.1002/pon.1626. [PubMed: 19916163].

17. King DB. Rething claims of spiritual intelligence: A definition model and measure. Trent University; 2008.

18. Sobhi Gharamaleki N, Porzur P. A comparison of spiritual intelligence and emotional intelligence of college students and religious students. Cult Islamic Univ. 2014;4(11):297-310.

19. Rahimi Pour M, Karami E. The Mediating Role of Spiritual Intelligence with Psychological well-being and life satisfaction in Mehriz Elderly people [In Persian]. Rehab Med. 2014;3(3):72-81.

20. Ball J, Armistead L, Austin BJ. The relationship between religiosity and adjustment among African-American, female, urban adolescents. J Adolesc. 2003;26(4):431-46. doi: 10.1016/S0140-1971(03)00037X. [PubMed: 12887932].
21. Hassanzadeh R, Fruzan S, Khademlu A. Use of psychological and personality tests. Tehran: Arasbaran; 2014

22. Sahebalzamani M, Farahani H, Abasi R, Talebi M. The relationship between spiritual intelligence with psychological well-being and purpose in life of nurses. Iran J Nurs Midwifery Res. 2013;18(1):38-41. [PubMed: 23983726].

23. Safavi M, Yahyavi SH, Fatehi Narab H, Yahyavi ST, editors. Relation between spiritual intelligence and depression coping style in patients with cancer in university hospitals of tehran university of medical science. International Conference of Social Science, Medicine and Nursing Istanbul. 2015; Turkey. .

24. Sim TN, Loh BSM. Attachment to God; measurement and dynamics. Journal Social and Personal Relationships. 2009;20(7):373-89.

25. Abedini H, Jomehrri F, Mojtabaei M. The role of spiritual intelligence in prediction of pain perception in cancer patients. Asian J Res Soc Sci Hum. 2015;5(2):229-35. doi:10.5958/2249-7315.2015.00040.4.

26. Charkhabi M, Mortazavi A, Alimohammadi S, Hayati D. The effect of spiritual intelligence training on the indicators of mental health in iranian students: An experimental study. Procedia Soc Behav Sci. 2014;159:355-8. doi: 10.1016/j.sbspro.2014.12.387.

27. Michaeli Manee F. The study of undergraduate students' psychological well-being status in Urmia University [In Persian]. Horizon Med Sci. 2011;16(4):65-73.

28. Shakarami M, Davarniya R, Zahrakar K. Predictor Factors of Psychological Well-being in Students [In Persian]. Q J Sabzevar Univ Med Sci. 2014;21(3):468-80.

29. McSherry W, Draper P, Kendrick D. The construct validity of a rating scale designed to assess spirituality and spiritual care. Int J Nurs Stud. 2002;39(7):723-34. doi: 10.1016/S0020-7489(02)00014-7. [PubMed: 12231029].

30. Amirian ME, Fazilat-Pour M. Simple and Multivariate Relationships Between Spiritual Intelligence with General Health and Happiness. J Relig Health. 2016;55(4):1275-88. doi: 10.1007/s10943-015-0004-y. [PubMed: 25616864].

31. Amram Y. The contribution of emotional and spiritual intelligences to effective business leadership. ;2009. 